\title{
Recreational activity after cementless total hip arthroplasty in patients older than 75 years
}

\author{
Alexander Zimmerer ${ }^{1,2}$ D $\cdot$ Luis Navas $^{1} \cdot$ Stefan Kinkel $^{1} \cdot$ Stefan Weiss $^{1} \cdot$ Matthias Hauschild $^{1} \cdot$ Wolfgang Miehlke $^{1}$. \\ Marcus Streit ${ }^{1}$
}

Received: 7 January 2021 / Accepted: 3 April 2021 / Published online: 3 May 2021

(c) The Author(s) 2021

\begin{abstract}
Introduction This retrospective study aimed to compare activity levels before and at mid-term follow-up after primary cementless total hip arthroplasty (THA) in patients older than 75 years.

Materials and methods A cohort of 79 patients with a mean age at surgery of 78 years (range 76-84 years) was evaluated 6.3 years (range 4-8 years) after cementless THA due to osteoarthritis and was followed up with a questionnaire to determine their activity level. Pre- and post-operative recreational activities were assessed at routine follow-up using the University of California, Los Angeles activity score, and the Schulthess Clinic sports and activity questionnaire. Post-operative healthrelated quality of life was measured using Veterans Rand 12-item survey (VR-12).

Results Six years after THA, 72\% of preoperatively active patients had returned to activity. Comparing activity preoperatively (before the onset of symptoms) and 6 years after THA, the number of disciplines and session length has decreased significantly. A significant decline in high-impact activities was observed, while participation in low-impact activities significantly increased.

Conclusion The majority of patients maintained a recreational activity level in the mid-term after primary cementless THA. However, a change in disciplines toward low-impact activities was observed.
\end{abstract}

Keywords Sport $\cdot$ Physical activity $\cdot$ Hip replacement $\cdot$ Mid-term $\cdot$ Old patient

\section{Introduction}

Total hip arthroplasty (THA) is one of the most successful orthopedic surgeries with an increasing caseload per year [1, 2]. As life expectancy rises, an increasing number of senior citizens are expected to participate in sports. The majority of patients' desire to maintain an active lifestyle and engage in sports after THA will increase. For younger patients, a high rate of return-to-activity after THA could be shown $[3,4]$. However, data on the activity level after cementless THA in patients older than 75 years are scarce in the literature. To the best of our knowledge, there are only data for

Alexander Zimmerer

zimmerer@sportklinik.de

1 ARCUS Sportklinik, Rastatterstr. 17-19, 75179 Pforzheim, Germany

2 Department of Orthopedics and Orthopedic Surgery, University Medicine Greifswald, Ferdinand-Sauerbruch-Straße, 17475 Greifswald, Germany short-term follow-up available [5]. Therefore, we conducted this study to analyze the return-to-activity rate and to assess the physical and recreational activity of patients older than 75 years undergoing primary cementless THA at mid-term follow-up. The hypothesis of our study was that the majority of patients treated by cementless THA would be able to return to regular recreational activity.

\section{Methods}

\section{Patient selection}

The present retrospective study comprises a cohort of 96 patients older than 75 years following primary cementless THA performed in a multi surgeon series (6 surgeons) between January 2012 and December 2014 at our institution (Fig. 1). Exclusion criteria were primary cemented or hybrid THA, revision surgery, and age at surgery of 74 years or younger. Six patients had died at a mean follow-up of 
Fig. 1 Flowchart illustrating the number of patients excluded from the study, lost to followup, and those who met inclusion criteria

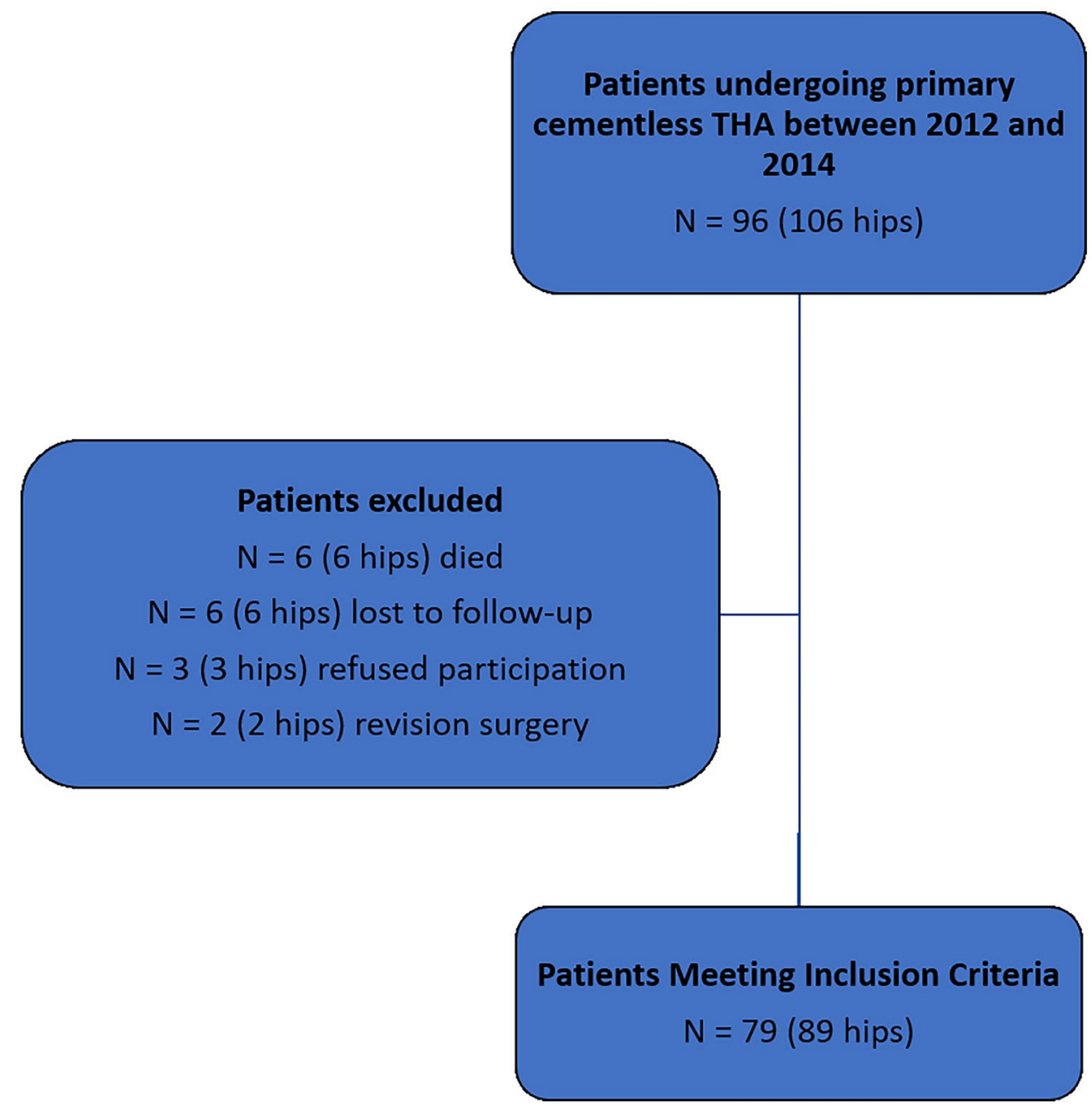

6.3 years (range 5-8), three patients refused to participate, and six patients were lost to follow-up. The THA failed in two patients during the study period and were therefore excluded from the study (one aseptic stem loosening, one septic revision), leaving 79 patients who were asked to complete the Schulthess Clinic Activity Score [6] and the Veterans Rand 12-Item Health Survey (VR-12) Physical Component Score (PCS) and Mental Component Score (MCS) [7]. The Schulthess Clinic Activity Score determines the athletic ability before the beginning of the symptoms with the present condition. In addition, patients' physical activity was prospectively assessed using the University of California, Los Angeles activity scale (UCLA) [8]. Activities such as skiing or cycling were defined as high-impact sports, while activities such as walking or ergometer training were defined as low-impact sports.

All patients gave informed consent. The ethics commission of the Landesaerztekammer Baden-Wuerttemberg, Germany, approved all procedures (F-2019-006), and the study was conducted following the Helsinki Declaration of 1975 , as revised in 2008 .
All patients received a cementless cup and a cementless femoral component. A cementless Corail stem (Depuy Orthopaedics, Warsaw, Indiana, USA) was used in all hips. A cementless Allofit acetabular cup (Zimmer, Warsaw, Indiana, USA) was used in 8 hips and a Pinnacle acetabular cup (Depuy Orthopaedics, Warsaw, Indiana, USA) in 81 hips, respectively. Ten patients received bilateral THA. A minimal-invasive posterior approach was used in 28 hips, a transgluteal Bauer approach in 40 patients, and a direct anterior approach (DAA) in 21 patients. Recommendations for return to activities following THA met the consensus guidelines from members of the Hip Society and the American Association of Hip and Knee Surgeons [9].

\section{Statistics}

Descriptive statistics for all continuous variables were reported as means (rang). Differences between preoperative and post-operative data were examined with a $t$ test and Wilcoxon signed-rank test. Categorical variables were reported using count and percentage. McNemar test was conducted 
to detect differences. A post hoc power analysis resulted in a power of 0.85 with an alpha error of 0.05 and an effect size of 0.3 due to the given sample size. Statistical analyses were conducted using SPSS statistical software (IBM SPSS Statistics for Windows, version 26.0.0; IBM Corp).

\section{Results}

\section{Demographics}

A total of 79 patients (89 hips) met inclusion criteria and were included in the analysis (Fig. 1). The mean age was 78 (75-84) years, the mean body mass index (BMI) was 26.6 (20.2-41.8) $\mathrm{kg} / \mathrm{m}^{2}$, and the mean follow-up was 6.3 (4-8) years. Surgery was performed in 33 men and 46 women. The diagnoses leading to arthroplasty were primary osteoarthrosis in 81 and secondary osteoarthrosis due to congenital

Table 1 Patient demographic data

\begin{tabular}{lc}
\hline & Value \\
\hline Total no. of patients & 79 (89 hips) \\
Laterality, $n(\%)$ & \\
Right & $46(52)$ \\
Left & $43(48)$ \\
Sex, $n(\%)$ & \\
Male & $33(42)$ \\
Female & $46(58)$ \\
Age, year & $78(75-84)$ \\
Body mass index, $\mathrm{kg} / \mathrm{m}^{2}$ & $26.6(20.2-41.8)$ \\
Follow-up time, year & $6.3(5-8)$ \\
\hline
\end{tabular}

Values are shown as $\mathrm{n}(\%)$, respectively, as the mean $\pm \mathrm{SD}$ (range) dysplasia of the hip in 8 hips. Forty-six THAs were performed on the right side, 43 on the left side (Table 1).

\section{Recreational activities}

For a total of 79 patients, a complete questionnaire regarding recreational activity was available. After surgery, 56 of 79 patients $(71 \%)$ were active in at least one recreational activity, compared with 78 of 79 (99\%) preoperatively, giving a return-to-activity rate of $72 \%$. None of the patients who had been inactive before surgery took up new sporting and recreational activities postoperatively. Patients performed an average of one different sport disciplines at the last follow-up, which differed significantly from the number before the onset of the first symptoms (3.4 disciplines; $p<0.0001)$. This significant decline was confirmed in the individual consideration of men and women, respectively (Fig. 2). Concerning single disciplines, outdoor activities such as hiking and biking revealed a significant decrease $(p<0.0001)$. In contrast, short walks increased significantly $(p<0.001)$ (Tables 2 and 3). Seventy-two percent of the patients returned to recreational activities within 1 month after surgery, and $26 \%$ resumed sporting activities within 3 months.

\section{Extent of activities}

The sports frequency (sessions per week) decreased significantly from the level before the onset of the first symptoms to the current state: patients were active 3.1 times before the onset of the first symptoms and 1.8 times postoperatively per week, respectively $(p<0.0001)$. When analyzing the subgroups, male patients participated more often in sports than female patients at the last follow-up, though this difference
Fig. 2 Number of sport disciplines patients participated in before the onset of the first symptoms and after cementless THA. The number of sport disciplines decreased significantly. Asterisks indicate significance $(p<0.0001)$

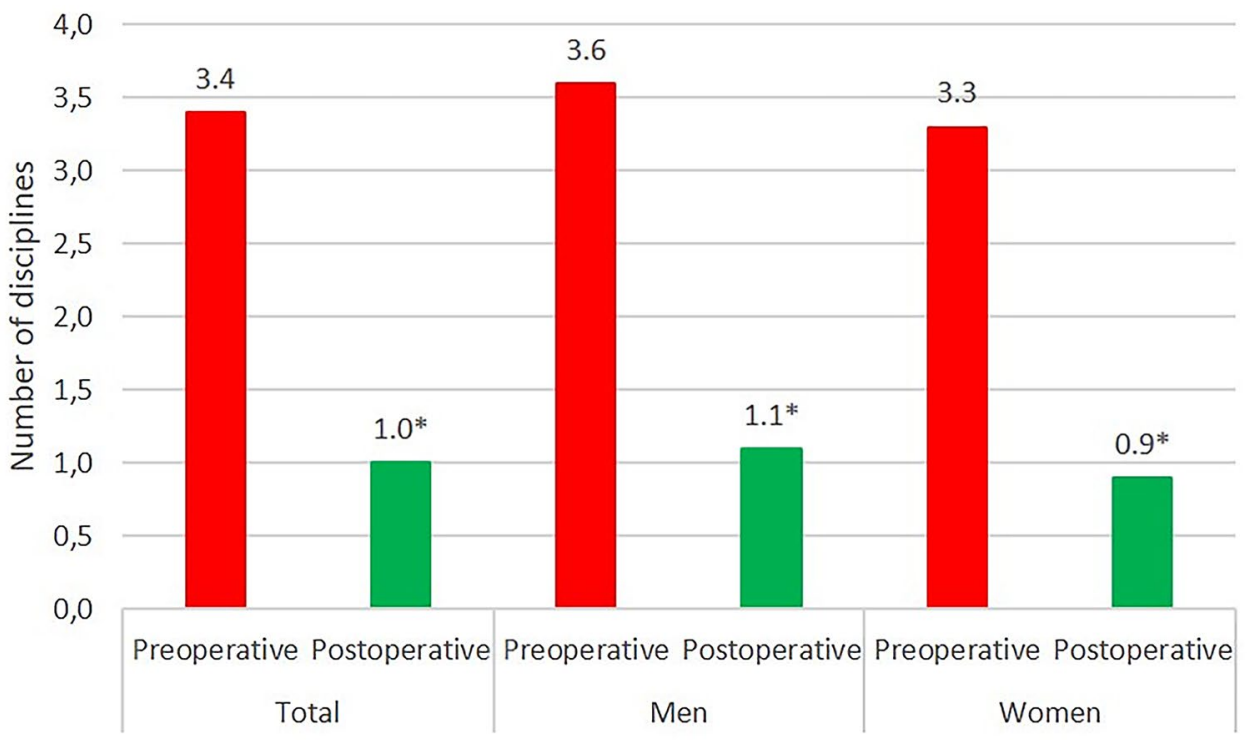


Table 2 Sports disciplines patients participated in before and after cementless total hip arthroplasty $^{\mathrm{a}}$

\begin{tabular}{lclc}
\hline Sports discipline & $\begin{array}{l}\text { Numbers of patients partici- } \\
\text { pating before surgery }\end{array}$ & $\begin{array}{l}\text { Numbers of patients partici- } \\
\text { pating after surgery }\end{array}$ & Difference (\%) \\
\hline Fitness training & 58 & 20 & $-75^{\mathrm{b}}$ \\
Short walks & 2 & 16 & $+700^{\mathrm{b}}$ \\
Long walks & 62 & 13 & $-79^{\mathrm{b}}$ \\
Ergometer training & 8 & 11 & +38 \\
Swimming & 40 & 11 & $-73^{\mathrm{b}}$ \\
Biking & 61 & 9 & $-85^{\mathrm{b}}$ \\
Gymnastics & 2 & 4 & +100 \\
Hiking & 40 & 0 & $-100^{\mathrm{b}}$ \\
Nordic walking & 17 & 0 & $-100^{\mathrm{b}}$ \\
\hline
\end{tabular}

${ }^{a}$ Several disciplines demonstrated significant decrease, which was mainly observed in outdoor sports. There was a significantly increase in short walks

${ }^{\mathrm{b}}$ Significant $(p<0.0001)$
Table 3 Top sports disciplines of different patient groups before and after cementless total hip arthroplasty ${ }^{\mathrm{a}}$

\begin{tabular}{lccc}
\hline & $\begin{array}{l}\text { Preoperative } \\
\text { participation } \\
\text { (\% of patients) }\end{array}$ & $\begin{array}{l}\text { Postoperative } \\
\text { participation } \\
\text { (\% of patients) }\end{array}$ & Difference (\%) \\
\hline Top sports in men & & & \\
Long walks & 78 & 16 & $-79^{\mathrm{b}}$ \\
Biking & 78 & 13 & $-83^{\mathrm{b}}$ \\
Fitness training & 72 & 28 & $-61^{\mathrm{b}}$ \\
Swimming & 47 & 16 & $-66^{\mathrm{c}}$ \\
Short walks & 3 & 25 & $+833^{\mathrm{b}}$ \\
Top sports in women & & $-100^{\mathrm{b}}$ \\
Long walks & 77 & 0 & $-87^{\mathrm{b}}$ \\
Biking & 75 & 10 & $-68^{\mathrm{b}}$ \\
Fitness training & 73 & 23 & $-85^{\mathrm{b}}$ \\
Swimming & 52 & 8 & $-100^{\mathrm{b}}$ \\
Hiking & 50 & 0 & $+750^{\mathrm{b}}$ \\
Short walks & 2 & 17 & \\
\hline
\end{tabular}

${ }^{a}$ Several disciplines demonstrated significant decrease, which was mainly observed in outdoor sports. There was a significantly increase in short walks in male and female patients

${ }^{\mathrm{b}}$ Significant $(p<0.0001)$

${ }^{\mathrm{c}}$ Significant $(p=0.002)$

was not significant (2.1 vs. 1.7 times per week, respectively, $p=0.354$ ). (Fig. 3).

The overall minimum session length decreased from $32 \mathrm{~min}$ before surgery to $17 \mathrm{~min}$ at the last follow-up $(p<0.0001)$. In addition, minimum session length decreased in male and female patients (Fig. 4).

As a reason for less physical activity, 55\% stated that they were less physically capable, $40 \%$ were more anxious, and $14 \%$ indicated feeling insecure. Eighty-nine percent of the patients reported an improvement in sporting and recreational activity due to the THA.

\section{Analysis of pre- versus postoperative patient-reported outcome score measurements}

Analysis of preoperative and at follow-up reported UCLA Score demonstrated statistically significant improvement from $3.3(1-8)$ preoperatively to 3.7 (1-6) at last follow-up $(p<0.007)$. None of the patients were highly active with a UCLA Score $\geq 7$. The post-operative rating of the VR-12 PCS was 43.5 (18.5-56.6) and MCS 41.8 (30.8-52.3) points.

\section{Discussion}

Life expectancy is rising in general, so that it can be assumed that an increasing proportion of the population will need a THA. Besides, it can be assumed that the proportion of pensioners who engage in sporting activities will increase. However, data on the activity level after cementless THA in patients older than 75 years are scarce in the literature.

The present study's main findings are that a large majority of patients could return to any manner of recreational behavior after cementless THA. We could demonstrate a returnto-activity rate of $72 \%$ at the latest follow-up (6.2 years). As stated before, there are little data available for this age cohort. Ortmaier et al. reported a return-to-activity rate of 92\% after cementless short-stem THA [5]. In their study, three age groups $(<60,60-70$, and $>70)$ were analyzed, whereby the return-to-activity rate was not differentiated between the individual age groups. Considering the overall return-to-sport rate in the literature, a decrease in sports activity was also reported for younger patients after THA $[10,11]$.

Looking at the level of physical activity in more detail, there was a shift from high-impact to low-impact activities. The most popular activities after surgery were short walks and indoor activities. These activities were in line 
Fig. 3 Number of sports sessions patients participated in before the onset of the first symptoms and THA. The average number of sports sessions decreased significantly after cementless THA implantation. Asterisks indicates significance $(p<0.0001)$

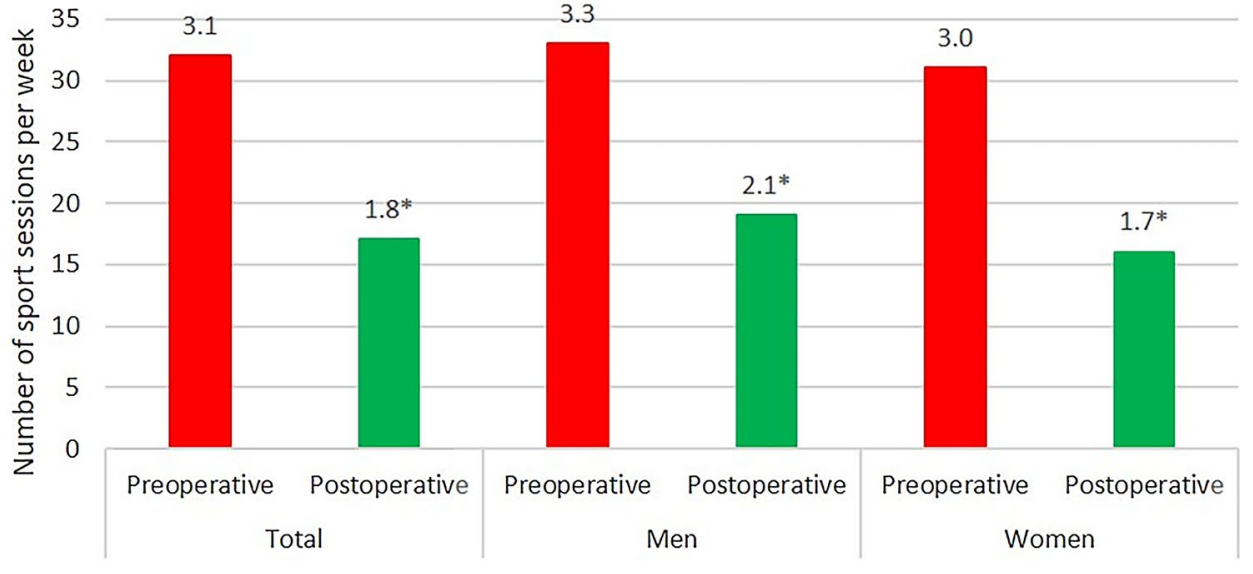

Fig. 4 Minimum length of each sport session before the onset of the first symptoms and after cementless THA. Asterisks indicate significance $(p<0.0001)$

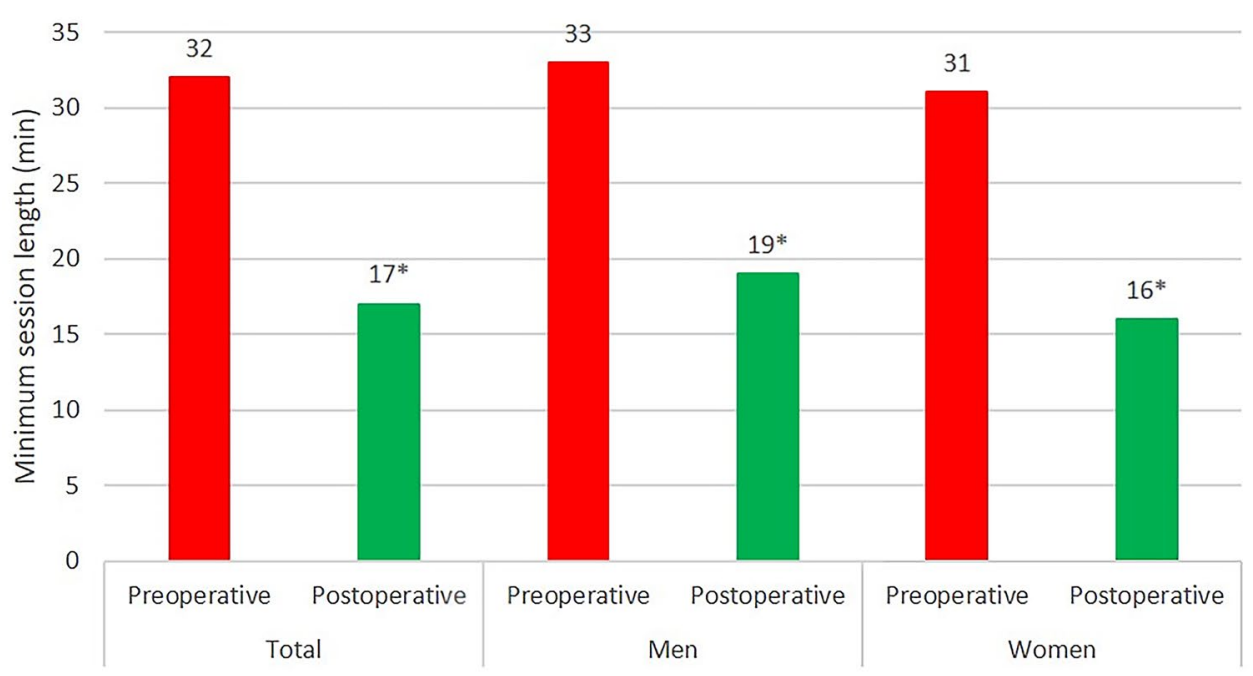

with the Hip Society members' consensus guidelines and the American Association of Hip and Knee Surgeons [9]. The decrease in high-impact activity is consistent with the results described in the literature $[5,12,13]$.

In total, the frequency and the session length changed significantly post-operative for both men and women. The activity frequency and the session length after surgery significantly decreased for male and female patients. Ortmaier et al. were able to show that the older group displayed a lower frequency and duration of recreational activity [5]. When patients were asked for the reasons for the change in their activities, they reported a high level of anxiety and reduced physical resilience. Even though the overall volume and intensity decreased, $89 \%$ of the patients stated an improvement in sporting and recreational activity due to the THA compared to the initial situation before surgery. In general, participation in sport declines with age $[14,15]$. Cross-sectional studies reported lower sports participation in people with higher age [16-18], and older age groups are less likely to be regularly active $[19,20]$.
Thereby, women seem to be less likely than men to achieve regular physical activity [21].

In the present study, PROMs were also evaluated to survey sporting activity. The UCLA activity score significantly improved in our patients (3.3-3.7 points), but none of the patients were highly active with a UCLA Score $\geq 7$. Ortmaier et al. reported a mean UCLA activity score of 6.2 for patients $>70$ years after a mean follow-up of 20 months, which was significantly lower than the younger groups' scores [5]. The present study's lower UCLA activity score may be because our cohort exhibits a higher average age than Ortmaier's group (mean age 78 vs. 74 years) and is less active due to age. The VR-12 MCS and PCS were analyzed at the latest follow-up. The achieved scores [PCS 43.5 (18.5-56.6), MCS 41.8 (30.8-52.3)] are comparable to those reported in the literature for the general population of the equivalent age.[22].

There are several limitations of this study. First of all, the study was designed in a retrospective manner, and patients reported on sport and recreational activities in which they 
might have been active years before. However, this is due to the questionnaire concept, which has been described previously and is commonly accepted. It must also be noted that the time of the first symptoms, as assessed in the questionnaire used, may have been several years ago. Besides, the preoperative VR-12 questionnaire is lacking. Finally, the patients were not clinically examined for the final follow-up, but only with a questionnaire, and there was no radiological examination at the time of follow-up. Another point worth mentioning is the variety of approaches used, which could potentially influence the results. However, the number of individual groups was too small to carry out a dedicated analysis. Our study's strength is that it provides detailed information on physical activity after cementless THA in patients older than 75 years, a population for which there are scarcely any data available.

\section{Conclusions}

There is a lack of information on activity in patients older than 75 years receiving THA. We could demonstrate that a large proportion returns to recreational activity and maintains the level in the mid-term follow-up. However, there was a significant decrease in the number of sport disciplines, the frequency, and duration of the sports sessions from preoperatively to postoperatively. Most patients were engaged in low-impact activities.

Acknowledgements We thank Dr. Marcus Vollmer (Institute of Bioinformatics, Greifswald, Germany) for his support regarding statistical analysis.

Funding Open Access funding enabled and organized by Projekt DEAL. Funding was not applicable.

\section{Declarations}

Ethical approval This study was approved by IRB/Ethikkommission Landesärztekammer Baden-Württemberg, Germany.

Open Access This article is licensed under a Creative Commons Attribution 4.0 International License, which permits use, sharing, adaptation, distribution and reproduction in any medium or format, as long as you give appropriate credit to the original author(s) and the source, provide a link to the Creative Commons licence, and indicate if changes were made. The images or other third party material in this article are included in the article's Creative Commons licence, unless indicated otherwise in a credit line to the material. If material is not included in the article's Creative Commons licence and your intended use is not permitted by statutory regulation or exceeds the permitted use, you will need to obtain permission directly from the copyright holder. To view a copy of this licence, visit http://creativecommons.org/licenses/by/4.0/.

\section{References}

1. Learmonth ID, Young C, Rorabeck C (2007) The operation of the century: total hip replacement. The Lancet 370(9597):15081519. https://doi.org/10.1016/S0140-6736(07)60457-7

2. Kurtz S, Ong K, Lau E et al (2007) Projections of primary and revision hip and knee arthroplasty in the United States from 2005 to 2030. J Bone Joint Surg 89(4):780-785. https://doi.org/ 10.2106/JBJS.F.00222

3. Innmann MM, Weiss S, Andreas F et al (2016) Sports and physical activity after cementless total hip arthroplasty with a minimum follow-up of 10 years. Scand J Med Sci Sports 26(5):550-556. https://doi.org/10.1111/sms.12482

4. Rueckl K, Liebich A, Bechler U et al (2020) Return to sports after hip resurfacing versus total hip arthroplasty: a mid-term case control study. Arch Orthop Trauma Surg 140(7):957-962. https://doi.org/10.1007/s00402-020-03414-6

5. Ortmaier R, Pichler H, Hitzl W et al (2017) Return to sport after short-stem total hip arthroplasty. Clin J Sport Med. https://doi. org/10.1097/JSM.0000000000000532

6. Naal FD, Fischer M, Preuss A et al (2007) Return to sports and recreational activity after unicompartmental knee arthroplasty. Am J Sports Med 35(10):1688-1695. https://doi.org/10.1177/ 0363546507303562

7. Boston University School of Public Health VR-36, VR-12 and VR-6D. (2015) Boston University School of Public Health Web site. http://www.bu.edu/sph/research/research-landing-page/ vr-36-vr-12-and-vr-6d/

8. Zahiri CA, Schmalzried TP, Szuszczewicz ES et al (1998) Assessing activity in joint replacement patients. J Arthroplasty 13(8):890-895. https://doi.org/10.1016/S0883-5403(98) 90195-4

9. Klein GR, Levine BR, Hozack WJ et al (2007) Return to athletic activity after total hip arthroplasty. J Arthroplasty 22(2):171175. https://doi.org/10.1016/j.arth.2006.09.001

10. Huch K (2005) Sports activities 5 years after total knee or hip arthroplasty: the Ulm Osteoarthritis Study. Ann Rheum Dis 64(12):1715-1720. https://doi.org/10.1136/ard.2004.033266

11. Wylde V, Blom A, Dieppe P et al (2008) Return to sport after joint replacement. J Bone Joint Surg Br Vol 90-B(7):920-923. https://doi.org/10.1302/0301-620X.90B7.20614

12. Schmidutz F, Grote S, Pietschmann M et al (2012) Sports activity after short-stem hip arthroplasty. Am J Sports Med 40(2):425-432. https://doi.org/10.1177/0363546511424386

13. Donner S, Rehbein P, Schneider M et al (2019) Return to sports and recreational activity after single-stage bilateral short-stem total hip arthroplasty: 5-year results of a prospective observational study. Orthop J Sports Med 7(9):232596711987274. https://doi.org/10.1177/2325967119872746

14 Caspersen CJ, Pereira MA, Curran KM (2000) Changes in physical activity patterns in the United States, by sex and crosssectional age. Med Sci Sports Exercise. https://doi.org/10.1097/ 00005768-200009000-00013

15. Jenkin CR, Eime RM, Westerbeek H et al (2017) Sport and ageing: a systematic review of the determinants and trends of participation in sport for older adults. BMC Public Health 17(1):391. https://doi.org/10.1186/s12889-017-4970-8

16. Palacios-Ceña D, Fernandez-de-las-Peñas C, Hernández-Barrera V et al (2012) Sports participation increased in Spain: a population-based time trend study of 21381 adults in the years 2000, 2005 and 2010. Br J Sports Med 46(16):1137-1139. https://doi.org/10.1136/bjsports-2012-091076

17. Scheerder J, Vanreusel B, Taks M (2016) Stratification patterns of active sport involvement among adults. Int Rev Sociol Sport 40(2):139-162. https://doi.org/10.1177/1012690205057191 
18. Breuer C, Wicker P (2009) Decreasing sports activity with increasing age?: findings from a 20-year longitudinal and cohort sequence analysis. Res Q Exerc Sport 80(1):22-31. https://doi. org/10.1080/02701367.2009.10599526

19 McGuire LC, Ahluwalia IB, Strine TW (2006) Chronic diseaserelated behaviors in U.S. older women: behavioral risk factor surveillance system 2003. J Women's Health 15(1):3-7. https:// doi.org/10.1089/jwh.2006.15.3

20. Mummery WK, Kolt G, Schofield G et al (2007) Associations between physical activity and other lifestyle behaviors in older New Zealanders. J Phys Act Health 4(4):411-422

21. Sun F, Norman IJ, While AE (2013) Physical activity in older people: a systematic review. BMC Public Health 13(1):1244. https://doi.org/10.1186/1471-2458-13-449
22. Austin DC, Torchia MT, Moschetti WE et al (2020) Patient outcomes after total hip arthroplasty in extreme elderly patients older than 80 years. Hip Int 30(4):407-416. https://doi.org/10. $1177 / 1120700019837943$

Publisher's Note Springer Nature remains neutral with regard to jurisdictional claims in published maps and institutional affiliations. 